\title{
ANALYSIS OF THE ACTIVITIES OF SITE AND PROJECT MANAGERS - IMPLICATIONS FROM THE PERSPECTIVE OF CREATING VALUE
}

\author{
Marco Binninger ${ }^{1}$, Janosch Dlouhy ${ }^{2}$, Johannes Schneider ${ }^{3}$, and Shervin Haghsheno ${ }^{4}$
}

\begin{abstract}
Construction projects are complex and include various processes, which have to be managed by a construction team. The position of a site manager or project manager (below we will use the term construction manager (CM)) plays an important role for the success of projects, because this position has the responsibility for the process organisation within the project. Studies show construction managers are typically exposed to a high level of stress. One German study from 1997 shows clearly the degree and effects of a high stress level. A major factor for inefficiency and a catalyst for stress could be a lack of transparency and missing communication inside a construction team.

The paper describes the results of a study of the daily activities of construction managers. Six individuals were accompanied and interviewed. In total 55 hours of observation have been undertaken to analyse the daily routine at this organisational level in projects. Based on the results of this analysis the authors propose improvements for construction managers. The proposal is based on the idea to structure the daily work routine of a construction manager. This helps to reduce the frequent changes and interruptions in activities, so construction managers can concentrate on value creating activities.
\end{abstract}

\section{KEYWORDS}

Site manager, project manager, stress, daily routine, transparency, daily meetings

\section{INTRODUCTION AND STRUCTURE OF THE PAPER}

The position of a construction manager plays an important role in the management and coordination of construction projects. This key position has a very wide spectrum of tasks and a high level of responsibility. A high rate of staff turnover and sick leave compared to

\footnotetext{
Research Fellow, Karlsruhe Institute of Technology, Germany, marco.binninger@googlemail.com Research Fellow, Karlsruhe Institute of Technology, Germany, janosch.dlouhy@bmw.de M.Sc. Student, Karlsruhe Institute of Technology, Germany, johannes.schneider6@student.kit.edu Professor, Karlsruhe Institute of Technology, Germany, shervin.haghsheno@kit.edu
} 
other positions in the construction industry are measurable effects of the high level of stress placed on construction managers (Strobel \& Krause 1997). In the first part of this paper the existing situation of the daily activities of a construction manager is described. Additionally information on the fundamentals regarding the study of stress is given.

For this research, six construction managers were accompanied and observed for a total of 55 hours during their daily activities to enable discussion in terms of the current situation, including the influence of digitalization. The data was systematically recorded and validated through interviews. The findings and approach used are discussed in the body of the paper. The goal of this field study is a quantitative analysis of the daily activities of construction managers. A proposed solution to heightened stress levels and overwork is to increase value creation. According to Lean Thinking, waste in construction management must be recognized and eliminated. Various solutions with a focus on increasing the proportion of value generating activities in the daily activities of construction managers will be proposed. Thereby Lean Management approaches for early recognition of waste can be implemented. The result, which will be described in the final part of the paper, is a structured daily routine to serve as the basis for targeted communication and increased transparency within teams.

\section{FOUNDATION AND EXISTING SITUATION}

\section{EXISTING SITUATION}

Construction projects are dynamic systems characterized by unforeseeable situations and uniqueness. The bespoke character of a project and changing project participants lead to a lack of consistency and uniformity (Koskela 1992, 44-45; Nakagawa and Shimizu 2004, 12-13). The result is a lack of structure and standards. Insufficient transparency and defective communication on the part of the construction managers further intensify the situation and lead to waste in daily activities. Stress occurs if the site manager is not fully informed with respect to problems and their consequences and thereby unable to make decisions. This is an uncomfortable situation and increases the amount of effort needed to obtain information.

A second significant part of construction management is reacting to fluctuating construction processes. Changes at short notice due to disruptions occur on a regular basis. The construction manager must react and implement solutions quickly (Syben 2014, 82-84). In order to still achieve a project's goals for time, cost and quality, additional management effort is needed. Hence, the success of a project is highly dependent on effective management and therefore the construction manager holds a key position (Rösch 2014, 25). He is the main switchboard of the construction site and progress is highly dependent on his personal project management competencies. Complex tasks and ineffective communication together with changing requirements in daily activities lead to a high level of pressure and stress for construction managers.

The sickness rate in the German construction industry has risen continuously from $4.4 \%$ in 2006 to $5.5 \%$ in 2014 (Meyer et al. 2015, 412). This lies significantly above the overall average of 5.2\% recorded in 2014 (Meyer et al. 2015, 341). Comparatively the 
number of cases of construction industry workers unfit for work due to psychological illnesses rose by almost $130 \%{ }^{5}$ from 1995 to 2014 .

\section{THEORETICAL BACKGROUND OF STRESS}

Rudow $(2011,52)$ defines stress from a psychological perspective as a short or long-term condition of increased activeness, caused by experiencing danger or a threat which is thereby associated with unpleasant emotions. Stress can also be understood as a process in which a key role is taken by assessing and overcoming burdens (Rudow 2011, 52). As part of this individuals perceive a discrepancy between what is required of them, and the resources at their disposal. Stress is therefore a negative reaction to a (psychological) burden. Chronic incidences of stress can even lead to so called burnout.

It is known from research on stress, that long-term overwork can lead to reduced creativity, wellbeing and motivation to work. Typical effects on day-to-day work include lack of concentration, low tolerance for pressure, irritableness with colleagues, mistakes and unconsidered decisions (Strobel \& Krause 1997, 2).

In 1997 Germany's Federal Institute for Occupational Safety and Health $\left(\mathrm{BAuA}^{6}\right)$ commissioned a research project on the topic of "Psychological Strain on Employees with Management Responsibilities in the Construction Area of the Building Industry". The goal of the study was to determine and analyse the main stress factors. Moreover, the effects of psychological stress as well as ways to prevent and reduce these effects were described. These were compiled as a set of guidelines. Based on random surveying of 70 construction managers, responsibilities and stressors were ranked. In addition, they were asked to approximate how frequently specific stressors occurred and what short and longterm effects these had on the affected person. Furthermore, possible strategies and resources for stress prevention and problem solving approaches were recorded from the participants. The five most frequently named stressors were cost pressures, working under time pressure, disruptions to work, disruptions to the construction sites and making decisions based on insufficient information (Strobel \& Krause 1997). Due to the fact that the results are 21 years old and do not take into account rapid advances in IT and communication, the applicability of these results is questionable. For a better understanding of the current situation, an investigation of the current situation was carried out.

\section{FIELD-STUDY}

\section{METHOD}

The results of Germany's Federal Institute for Occupational Safety and Healthresearch serve as the starting point for further investigating and analysing the activities and level of stress of construction managers. For this purpose, six construction managers were observed carrying out their day-to-day tasks for a total of 55 hours. Thereby 371 activities

Own calculations. Data source: Meyer et al. 2015, 417

6 BAuA means Bundesanstalt für Arbeitsschutz und Arbeitsmedizin (Germany's Federal Institute for Occupational Safety and Health) 
could be assessed. It should be noted that the entire working day was recorded in order to gain an uninterrupted sample. The study is focused on construction managers for building projects in the areas of turnkey construction, shell construction and industrial buildings. Table 1 shows an overview of the six construction managers.

Table 1: Overview of the different construction managers

\begin{tabular}{|c|c|c|c|c|}
\hline $\mathbf{C M}$ & $\begin{array}{c}\text { Work } \\
\text { experience } \\
\text { in [years] }\end{array}$ & $\begin{array}{c}\text { Work } \\
\text { experience } \\
\text { in [number } \\
\text { of projects] }\end{array}$ & $\begin{array}{c}\text { Total project } \\
\text { volume in } \\
{[\text { Mio } €]}\end{array}$ & $\begin{array}{c}\text { Description of construction } \\
\text { project }\end{array}$ \\
\hline CM 1 & 4 & $<5$ & $<25$ & $\begin{array}{c}\text { Turnkey residential houses with } \\
\text { over } 70 \text { flats }\end{array}$ \\
\hline $\mathrm{CM} 2$ & 23 & $5-20$ & $25-100$ & Four turnkey residential houses \\
\hline CM 3 & 25 & $>20$ & $>100$ & $\begin{array}{l}\text { Structural works of Multi- } \\
\text { functional education building }\end{array}$ \\
\hline $\mathrm{CM} 4$ & 4 & $5-20$ & $<25$ & $\begin{array}{l}\text { Industrial building with storage } \\
\text { and production hall }\end{array}$ \\
\hline CM 5 & 10 & $>20$ & $<25$ & Renovation of retail area \\
\hline CM 6 & 3 & $5-20$ & $<25$ & Turnkey office building \\
\hline
\end{tabular}

Table 1 shows the diversity of the experience of the construction managers and the projects. The majority of construction sites were at an advanced stage of execution. All companies of the surveyed construction managers had more than 250 employees.

In the next step a suitable method of observation was defined. As the work of construction manager varies through the day and is characterized by frequent task changes, precise recording of data required a digital solution. The application "Bauleiter Monitoring" freely available in the Apple App Store was selected ${ }^{7}$. Using the app allows passive participation as well as structured and open observation (Atteslander \& Cromm 2008, 85-87). Thereby it is possible to separate the researcher and observer. This allows the chance for different persons to review the same observations and compare conclusions. It further allows verifiability of the observations (Atteslander \& Cromm 2008, 77).

Before observations took place, a briefing session with each construction manager was held. The exact method was described and a suitable day for observation was agreed to allow the observations to be as representative as possible. Additionally, the construction manager was advised to behave as normal as possible and not to make contact with the observer. The observation allowed each individual process to be observed second by second. In a preliminary stage 160 process types were identified with the help of various literature.

${ }^{7}$ Retrieved on 16.11.2016. No longer accessbile since 2017 
After completing the observations, each construction manager was interviewed for approximately 35 minutes. Research hypotheses that could not be tested using the application were discussed in greater detail by conducting a semi-structured interview.

\section{RESULTS OF THE STUDY}

The results of the study show that frequent changes between different tasks, long working hours, increased effort for particular tasks and frequent disruptions are characteristic of the working day of construction managers. Figure 1 shows the average duration of a process (one task) per construction manager.

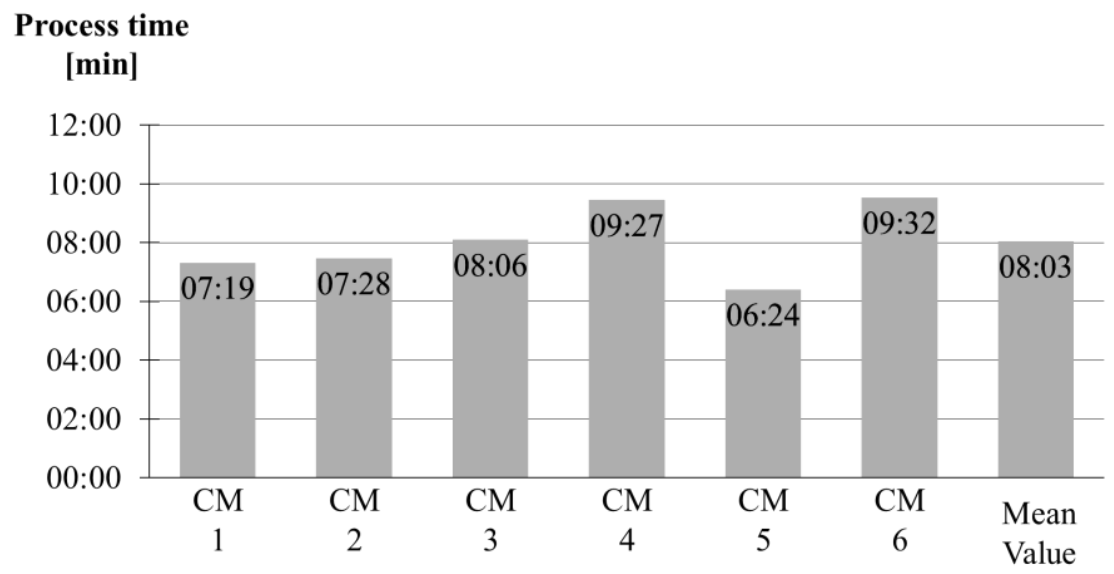

Figure 1: Average process duration CM 1-6

The mean value for all construction managers is 8:03 minutes. Changing processes can also be caused due to interruptions. The construction manager's influence on when to change tasks is therefore limited, and on average he changes tasks 7.6 times per hour. Frequently changing tasks can therefore be seen as a key requirement for construction managers and leads to a situation of increased strain. The construction managers were interrupted due to external factors every 35 minutes. Normalized to an eight-hour working day, this results in 15 interruptions per day. Figure 2 shows the percentage distribution of the causes of interruptions. Phone calls were responsible for almost half $(46 \%)$ of all interruptions while $36 \%$ were caused by personnel. Furthermore, it was investigated whether the same task was continued after each interruption. A mean of $60 \%$ of interrupted tasks were continued.

Five of the six construction managers did not agree that the tasks given to them could be achieved within their contractual working hours (without overtime). This is supported by the number of working hours recorded which has a mean of 8:28 hours. This value was lower than expected as CM1 had a significantly reduced working day due to private circumstances. When excluding CM1 the mean value for CM 2-6 is 8:55 hours or five overtime hours per week. Despite the high number of overtime hours, only approximately two thirds of the entitled breaks were actually used. 


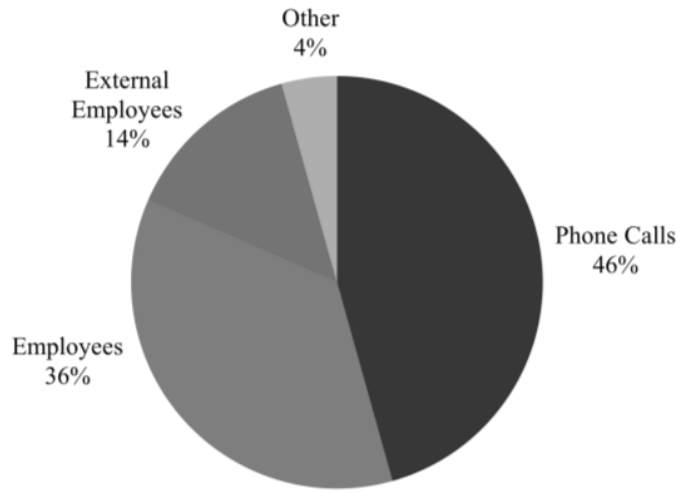

Figure 2: Percentage distribution of causes of interruptions for CM 1-6

Communication by email and (mobile) phone took up approximately $25 \%$ of total working time. According to the construction managers, there is an expectation on construction sites that they should be immediately reachable by mobile phone at all times. It is characteristic for all of the construction managers that they complete typical tasks from various project phases at the same point in time.

\section{IMPLICATION OF THE STUDY}

The activities of construction managers do not directly generate value but rather support creation of value on construction sites. The results of the observations show that the daily activities of construction managers did not have any structure and the various processes were not standardized. A lack of standardized construction site processes prevents construction management from being more structured. If the construction site is unstructured, so is the organization of the construction manager's work. The work of the construction manager becomes more focused on reacting to situations and less on structured actions. Excessive switching between tasks and interruptions to work cause increased strain and prevent optimal management of the construction site. The following will address these topics in detail from an occupational science perspective. According to the construction managers surveyed, interruptions to work are stressors as these are followed by a phase of getting back into the task at hand. In complex tasks it is particularly difficult to return to the prior train of thought.

Research studies on the topic of disruptions to work show that interruptions lead to increased time needed to complete tasks, higher incidences of errors, forgetting tasks and an increase in negative emotions such as fear and anger (Baethge \& Rigotti 2013, 17). In general, multitasking is considered as frequent switching between tasks, and as soon as changing tasks is required, transitional costs occur which are generally expressed as lost time. The result is that multitasking leads to lost time in most cases (Baethge \& Rigotti 2013, 14). Researchers from the University of Michigan could demonstrate that the human brain is $20-40 \%$ less effective when two tasks are completed at the same time rather than one after the other (Baethge \& BAuA 2012, 12). If a person is distracted from a task for more than three minutes or decides to start a new task, approximately two minutes will be needed to return to the same state of the previous task. (Baethge \& BAuA 2012 , 14). Occupational scientists have already proven a correlation between longer 
working times and psychological stress (Lohmann-Haislah 2012, 113). Increased weekly working hours lead to an increase in perceived working intensity. Time and performance pressure increase and employees tend to feel overwhelmed by the amount or duration of work (Wöhrmann et al. 2016, 28-29). Furthermore, it could be shown that in the case of longer working hours, a higher number of breaks were skipped.

The cause of the effects described above can be found in the high level of fluctuation in tasks on construction sites as well as in disruptions to the construction process. These can lead to chaos on construction sites. Because of this the construction manager is frequently required to immediately react to seemingly unexpected problems. This requires a higher amount of management and concentration. Often problems are first recognized and eliminated when the consequences have already occurred, and the construction manager takes the role of a 'firefighter' (Hauser 2013, 8). The result is that construction managers have no chance of structuring their tasks and working days. Even smaller disruptions can spread and cause greater disruptions through the so-called bullwhip effect (Sterman 1989, 321-339).

'Firefighting' as a management approach can be effective in specific cases. However, this method cannot be efficient, and the additional effort required disrupts day-to-day tasks negating any gains made. Open and documented communication between project participants is usually lacking in practice. In this situation, the construction manager often functions as the 'main switchboard' of the construction site and coordinates his own team as well as external partners. All information-flows and decisions are managed by the construction manager. As soon as the level of complexity exceeds the competency of the construction manager, the system collapses. A more even sequence of construction, higher transparency between participants and short-cycled target/actual comparisons onsite can minimize these problems.

\section{STRUCTURE AS A SOLUTION FOR VALUE CREATION}

Creating value by reducing waste in the everyday activities of construction managers is a significant factor for optimizing their workload. The findings of this study point towards a need for improving the way construction managers' tasks are organized. A conceivable solution would be to arrange each workday into work blocks. The prioritization of the work blocks according to delivering value to the client and interlocking with construction site processes allows unnecessary works to be reduced or eliminated. Through the basic approaches of Lean Construction, the working approach used by construction managers can be planned more efficiently. The structure should reduce disruptions to work, the frequency of task changes and the number of overtime hours and therefore reduce stress on construction managers. The structured daily routine should give specific standards, but also be flexible enough to take into account individual circumstances of each construction manager. This study showed that the beginning of the workday is particularly suited to being structured. One way how this could be achieved is shown in Figure 4. This includes a site walkabout, 15 minutes of clearing e-mails and meetings with people from various levels of hierarchy. 


\begin{tabular}{|clc|}
\hline Time & Work & $\begin{array}{c}\text { Duration } \\
{[\mathrm{min}]}\end{array}$ \\
\hline $7: 15$ & E-Mail & 15 \\
\hline $7: 30$ & Construction Site Visit & 30 \\
\hline $8: 00$ & Takt Control Meeting & 15 \\
\hline $8: 15$ & Internal Meeting & 30 \\
\hline $8: 45$ & Morning Break & 15 \\
\hline $9: 00$ & Block of Work $\mathbf{1}$ & $\mathbf{9 0}$ \\
\hline $10: 30$ & Block of Work 2 & $\mathbf{9 0}$ \\
\hline of the \\
12:00 & Lunch Break & 45 \\
\hline $12: 45$ & E-Mail & 15 \\
\hline $13: 00$ & Block of Work 3 & $\mathbf{9 0}$ \\
\hline $14: 30$ & Block of Work 4 & $\mathbf{9 0}$ \\
\hline $16: 00$ & E-Mail & 15 \\
\hline $16: 45$ & Daily Planning & 30 \\
\hline
\end{tabular}

Figure 3: Example for Structured Daily Routine consisting of the Beginning of a Workday and of Blocks of Work

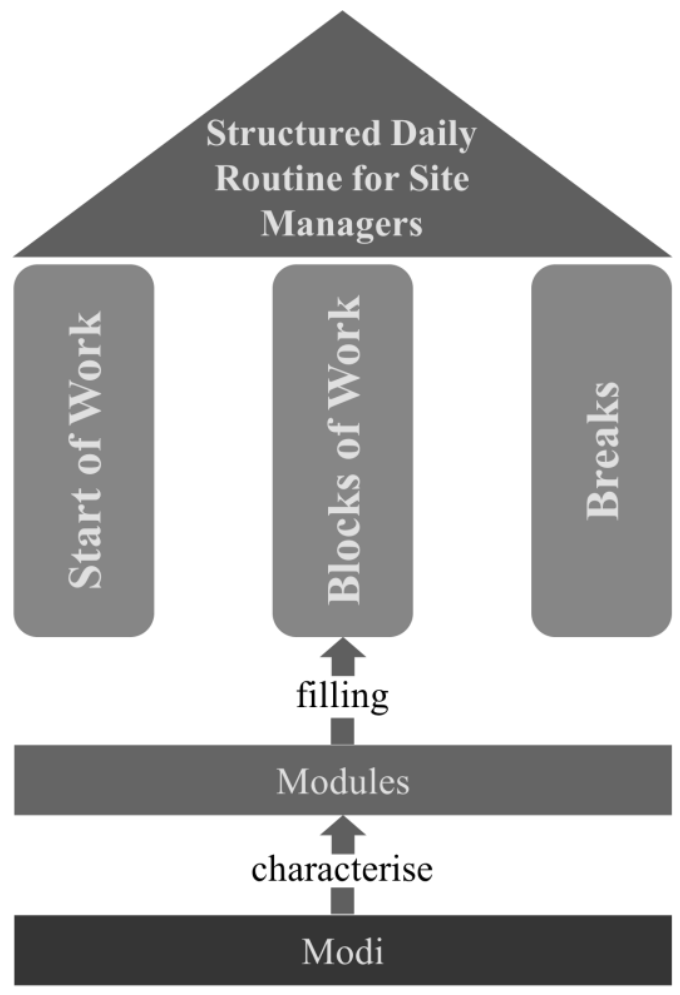

Figure 4: Fundamentals of a Structured Daily Routine

An example of this is the Takt Control meeting according to the method of Lean Construction described in detail by Binninger et al. (2016, 1-13). This is supported by visualizations and universal functionality. It provides an alternative to complex and chaotic systems that are difficult to implement due to language barriers. Possible obstacles and unclarities are identified well in advance and prevented before they are able to cause problems. The rest of the workday can be divided into multiple standard blocks as shown in Figure 3. Every work block is allocated a particular module, which allows a clear separation of construction site planning and construction site management. Different modes are defining the characteristics of each module. This allows an uninterrupted and concentrated working approach and thereby leads to a lower rate of errors and time saved during the workday. Figure 4 shows the stated fundamental requirements for a structured and standardized workday. The work blocks are suited to repeated longer tasks such as meetings or complex tasks that require a high level of concentration. These can be allocated to different modules and flexibly distributed across the day. The blocks are 90 minutes long. This time period is long enough to achieve the majority of a construction manager's tasks within one block (Cichos 2007, 175). Furthermore attention and concentration significantly decline after 90 minutes meaning longer blocks are not feasible (Brendt 2008, 95-96). Eachworking block can include different modules. One module defines construction management activities which have similarly high 
requirements. Due to modularisation, the daily routine is standardized which nevertheless allows great flexibility. The construction manager has many possible courses of action and the freedom to consider the actual on-site situation or the requirements of his employer.

The modes of each module provide a suitable framework for working conditions. Thereby the construction manager obtains greater control about getting interrupted, for example. This allows a significant reduction in disruptions and task changes as well as greater control over those that do occur. Stressors can be reduced while at the same time increasing the construction manager's working capacity. For example, the 'concentration' module allows for complex tasks to be carried out. These tasks should be carried out continuously and without interruption. A work block with the module 'routine' should be used for more simple tasks. Disruptions and changing tasks are possible, but should be minimized. For detailed descriptions of example modules and modes refer to Schneider (2016). However, the described daily routine is a theoretical approach. The ideal typical structured daily routine is not directly applicable, but rather demonstrates approaches that could be applied as suited.

\section{CONCLUSION AND OUTLOOK}

The field study shows a number of reasons for the high level of stress present in the construction management profession and gives a good overview of construction manager's every day activities. To better asses the existing situation, the observations must be carried out on a greater scale and over a longer period. The key to reducing stress on construction managers and an increase in value generated from their day-to-day tasks is particularly dependent on a structured working day. The proposed structured workday as described in this paper should be critically scrutinised and be adapted according to real-life situations. Other industry sectors have already implemented similar methods. The construction industry, in many areas, has not yet gained this level of understanding. Nevertheless, this structure helps with operating methods from Lean Construction such as Line of Balance, Takt Planning and Takt Control, and Last-Planner-System ${ }^{\circledR}$. Even in such systems, there must be enough time allowed for communication and sustainable approaches to problem solving. The contradiction between a classic construction management style and structured execution with Lean Principles could be determined on many occasions by the authors.

The factors named herein should not be considered in isolation, but rather are all interlinked. In this regard, this paper includes suggestions for possible courses of action to reduce stress on construction managers which in some instances still require testing and validation in practice.

\section{REFERENCES}

Atteslander, P., and Cromm, J. (2008). Methoden der empirischen Sozialforschung. [Methods of Empirical Social Research]ESV basics, E. Schmidt, Berlin, pp. 77, 85-87 (in German). 
Baethge, A., and BAuA (Eds.). (2012). Bitte nicht stören! Tipps zum Umgang mit Arbeitsunterbrechnungen und Multitasking[Do not disturb! Tips for dealing with work interruptions and multitasking]. BAuA, Dortmund, pp. 12, 14, (in German).

Baethge, A., and Rigotti, T. (2013). "Auswirkung von Arbeitsunterbrechungen und Multitasking auf Leistungsfähigkeit und Gesundheit: eine Tagebuchstudie bei Gesundheits- und KrankenpflegerInnen [Impact of work interruptions and multitasking on performance and health: a diary study of health and nurses]; Forschung Projekt F 2220.” Arbeitsunterbrechungen und Multitasking, pp. 14, 17 (in German).

Binninger, Marco; Dlouhy, Janosch; Karcher, Julian; Haghsheno, Shervin (2016):

Baustellensteuerung in getakteten Projekten nach Ansätzen des Lean Construction[Construction site control in taktes projects based on Lean Construction approaches]. in: R.Schach und P. Jehle (eds.): Tagungsband zum 27. BBBAssistententreffen. Dresden, 18.-20. May, pp. 1-13, (in German).

Brendt, D. (2008). Zeitmanagement für den Bauleiter: Mittel und Wege der Zeitplanung und Selbstorganisation - Zeitgewinn durch Führungstechniken Stressbewältigung[Time management for the site manager: means and ways of scheduling and self-organization - gaining time through leadership techniques managing stress]. Kontakt \& Studium, expert, Renningen, pp. 95-96 (in German).

Cichos, C. (2007). Untersuchungen zum zeitlichen Aufwand der Baustellenleitung: Ermittlung von Tätigkeiten und zugehörigen Aufwandswerten der Bauleitung auf einer Baustelle[Investigations on the time required by the construction site management: Determination of activities and associated expenses of construction management on a construction site], Dissertation, TU Darmstadt. Fachbereich Bauingenieurwesen und Geodäsie,pp. 175 (in German).

Hauser, Klaus (2013): Helden und Methoden - wie managen Sie Ihre Projekte[Hereos and methos - how do you manage your projects]. in: Ernst \& Young Real Estate GmbH: Unternehmen als Bauherren Project Controlling, Risk Management und Claim Management im Projekt, pp. 8 (in German)

Koskela, L. (1992). Application of the New Production Philosophy to Construction. Stanford University, pp. 44-45.

Lohmann-Haislah, A. (2012). Stressreport Deutschland 2012: psychische Anforderungen, Ressourcen und Befinden[Stress Report Germany 2012: psychological requirements, resources and well-being]. Stressreport Deutschland, Bundesanstalt für Arbeitsschutz und Arbeitsmedizin, Dortmund, pp. 113 (in German).

Meyer, M. et al. (2015): Krankheitsbedingte Fehlzeiten in der deutschen Wirtschaft im Jahr 2014 [Sickness absence in the German economy in 2014]. In Badura et al. (Hh.): Fehlzeiten-Report 2015: Neue Wege für mehr Gesundheit - Qualitätsstandards für ein zielgruppenspezifisches Gesundheitsmanagement. Berlin, Heidelberg. Springer, pp. 341, 412 (in German).

Nakagawa, Y., and Shimizu, Y. (2004). "Toyota Production System Adopted by Building Construction in Japan." XII Annual Conference of International Group for Lean Construction-IGLC, pp. 12-13. 
Rösch, P. (2014). "Bauleiter entlasten. [Relieve the site manager]" Deutsches Baublatt, (375), pp.25 (in German).

Rudow, B. (2011). Die gesunde Arbeit: Arbeitsgestaltung, Arbeitsorganisation und Personalführung [The healthy work: work structuring, work organization and personnel management]. Oldenbourg, München, pp. 52 (in German).

Schneider, J. (2016). Möglichkeiten und Grenzen der Einführung eines strukturierten und standardisierten Tagesablaufs[Opportunities and limitations in implementing a structured and standardized daily routine for construction managers], Bachelor Thesis, Kalrsruhe Institut of Technology, (in German).

Sterman, John David (1989): Modeling managerial behavior: Misperceptions of feedback in a dynamic decision making experiment. In: Management Science, vol. 35, no. 3, pp. 321-339.

Strobel, G., and Krause, J. von. (1997). Psychische Belastung von Bauleitern[Psychological stress of site managers] / G. Strobel; J. v. Krause, pp. 2 (in German).

Syben, G. (2014). Bauleitung im Wandel: Arbeit als Bewältigung von Kontingenz[Construction managment in transition: Work as coping with contingency]. Forschung aus der Hans-Böckler-Stiftung, Ed. Sigma, Berlin, pp. 82-84 (in German).

Wöhrmann, A. M., Gerstenberg, S., Hünefeld, L., Pund, F., Reeske-Behrens, A., Brenscheidt, F., and Beermann, B. (2016). Arbeitszeitreport Deutschland 2016[Working time report Germany 2016]. Verlag Kettler GmbH, Bönen, pp. 28-29 (in German). 